\title{
5-year audit of the range and volume of diagnostic radiographic services at the University of Nairobi Dental Hospital
}

\author{
Eunice N. Kihara ${ }^{1}$, Florence Opondo ${ }^{1}$, Tom J. Ocholla ${ }^{1}$, Mark L. Chindia ${ }^{2}$, Evelyn Wagaiyu ${ }^{3}$ \\ ${ }^{1}$ Radiology Division, Department of Oral \& Maxillofacial Surgery, Oral Pathology \& Medicine, University of Nairobi, Nairobi, Kenya \\ ${ }^{2}$ Department of Oral \& Maxillofacial Surgery, Oral Pathology \& Medicine, University of Nairobi, Nairobi, Kenya \\ ${ }^{3}$ Department of Periodontology, University of Nairobi, Nairobi, Kenya \\ Email: eunik20@yahoo.com
}

Received 10 July 2012; revised 11 August 2012; accepted 19 August 2012

\begin{abstract}
Background: Dental and cranio-maxillofacial diagnostic imaging constitutes an invaluable tool in the accurate diagnosis and management of a diverse range of conditions and diseases that afflict the oral and cranio-maxillofacial region. In order to improve on any existing facility, periodic audit evaluation is paramount. In this way proper and relevant service delivery can be achieved. Objective: To evaluate the range and volume of dental and cranio-maxillofacial diagnostic radiographic services offered at the University of Nairobi Dental Hospital (UNDH) in Kenya over a 5-year period (2006-2010). Methods: Retrospective survey involving manual examination of patient records at the Division of Dental and cranio-maxillofacial Radiology registry of the UNDH. Results: Over the study period, the range of diagnostic radiographic services offered comprised of both intra- and extraoral examinations. The total volume of radiographs taken was 48,874 among which $41,980(86 \%)$ were intraoral and $6894(14 \%)$ extraoral views. Among the intraoral views, $74 \%$ were bitewing, $25 \%$ periapical and only $1 \%$ were occlusal diagnostic views. The majority $(95 \%)$ of the extraoral projections consisted of panoramic views and only $5 \%$ constituted other techniques. The volume of radiographs was high from January to September while November and December had the lowest number of examination requests. Conclusion: Intraoral radiography was the commonest examination with bitewings having been the majority while the panoramic tomography was the commonest extraoral examination performed.
\end{abstract}

Keywords: Audit; Radiographs

\section{INTRODUCTION}

Dental and cranio-maxillofacial diagnostic imaging con- stitutes an invaluable tool in the assessment of a diverse range of conditions and diseases that afflict the oral and cranio-maxillofacial region. Various imaging modalities and techniques have been developed to achieve this purpose. They include intraoral and extraoral radiographic techniques as well as other advanced imaging modalities. The intraoral techniques comprise of bitewings (BW), intraoral periapical (IOPA) and occlusal views. Common extraoral projections include the lateral oblique, occipital mental (OMV), submentovertex (SMV), posteroanterior (PA) and lateral skull views in addition to the lateral cephalogram, temporalmandibular joint (TMJ) projections, pantomography and imaging of salivary glands $[1,2]$. Other advanced imaging modalities consist of computed tomography (CT), cone beam computed tomogramphy (CBCT), ultrasonography (US), magnetic resonance imaging (MRI), digital radiography, nuclear medicine, scanography, tomography and stereoscopy $[3,4]$. In order to improve on any existing imaging facility, periodic clinical audit is paramount. This could involve audits of pieces of equipment and all the radiographic processes such as selection criteria, techniques, workload, exposure parameters, radiation protection, processing of radiographs, diagnostic quality of images, record keeping and reporting of findings [5]. The aim of this study was to determine the range and volume of radiographic examination offered at University of Nairobi Dental Hospital (UNDH). The information obtained could play a significant role in the analysis of the UNDH radiology services as well as form a basis for revenue estimates and the investigative expenditure that should be anticipated by the institution's administration.

\section{MATERIAL AND METHOD}

Study site: the study was done at UNDH, division of Dental and Cranio-Maxillofacial Radiology. Method: This was a retrospective study which involved manual re- 
trieval of patients' records held at the Radiology Registry. This was followed by the assessment of the types of radiographs taken as well as recording of the number of radiographs taken on a monthly basis.

\section{RESULTS}

Over the 5-year study period, the range of diagnostic radiographic services offered comprised of intraoral and extraoral techniques. The total volume of radiographic investigations constituted 48,874 examinations among which 41,980 (86\%) were intraoral and 6894 (14\%) extraoral views (Table 1). Intraoral views consisted of 30,938 (74\%) bitewing views, 10,520 (25\%) periapical views and only 522 (1\%) occlusal diagnostic views (Table 2). Extraoral projections included panoramic views (Figure 1), cephalograms, OMV, SMV, PA and lateral oblique views of the jaws; lateral and PA skull views in addition to other specialised techniques. The majority 6566 (95\%) of the extraoral examinations consisted of panoramic views while only 328 (5\%) were other techniques (Table 3). The volume of radiographs varied from month to month as shown in Figure 2.

\section{DISCUSSION}

Oral and maxillofacial radiology continues to play a fundamental role in the diagnosis and management of diseases, disorders and conditions of the oral and maxillofacial region. In this study, the UNDH radiology facility was found to perform an annual average of 9775 radiographic exposures. Majority of the techniques consisted of intraoral examinations which are the backbone of im-

Table 1. Distribution of the number of intra- and extraoral views.

\begin{tabular}{cccc}
\hline Year & Intraoral & Extraoral & Total \\
\hline 2006 & 6188 & 1782 & 7970 \\
2007 & 8161 & 1896 & 10,057 \\
2008 & 11,116 & 2020 & 13,136 \\
2009 & 7695 & 1161 & 8856 \\
2010 & 8820 & 35 & 8855 \\
TOTAL & 41,980 & 6894 & 48,874 \\
$\%$ & $86 \%$ & $14 \%$ & $100 \%$ \\
\hline
\end{tabular}

Table 2. Distribution of the volume of intraoral views.

\begin{tabular}{ccccc}
\hline Year & Bitewing & Periapical & Occlusal & Total \\
\hline 2006 & 4442 & 1708 & 38 & 6188 \\
2007 & 6616 & 1482 & 63 & 8161 \\
2008 & 9122 & 1911 & 83 & 11,116 \\
2009 & 5216 & 2355 & 124 & 7695 \\
2010 & 5542 & 3064 & 214 & 8820 \\
TOTAL & 30,938 & 10,520 & 522 & 41,980 \\
$\%$ & $74 \%$ & $25 \%$ & $1 \%$ & $100 \%$ \\
\hline
\end{tabular}

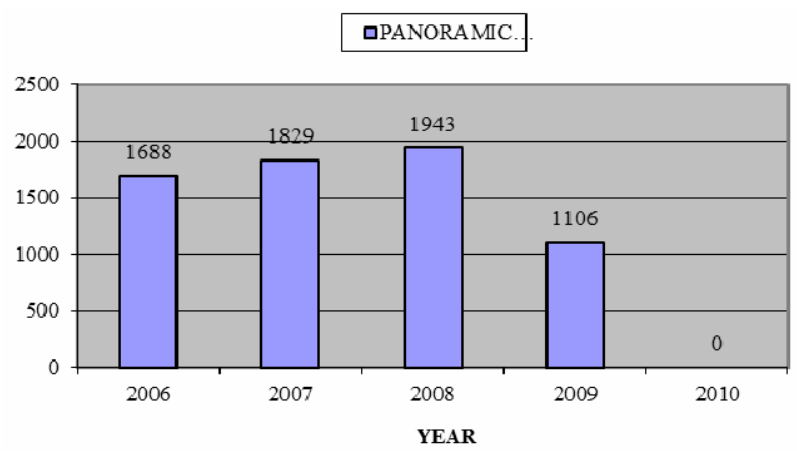

Figure 1. Volume of panoramic projections performed over the study period.

Table 3. Distribution of the number of extraoral views performed over the study period.

\begin{tabular}{cccc}
\hline YEAR & PANORAMIC & OTHER VIEWS & TOTAL \\
\hline 2006 & 1688 & 94 & 1782 \\
2007 & 1829 & 67 & 1896 \\
2008 & 1943 & 77 & 2020 \\
2009 & 1106 & 55 & 1161 \\
2010 & 0 & 35 & 35 \\
TOTAL & 6566 & 328 & 6894 \\
$\%$ & $95 \%$ & $5 \%$ & $100 \%$ \\
\hline
\end{tabular}

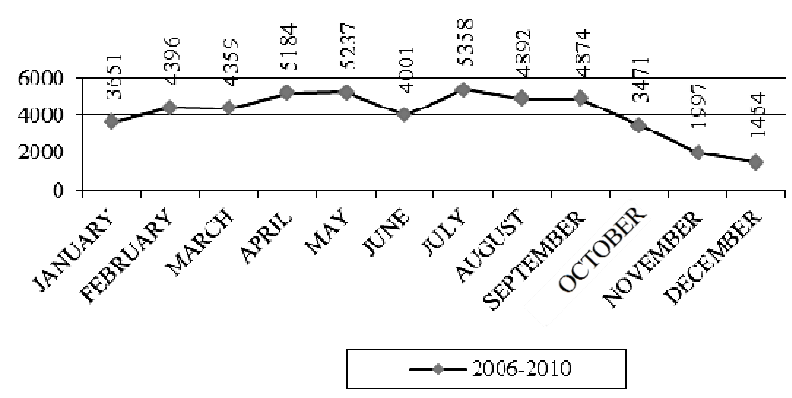

Figure 2. Distribution of radiographic images performed monthly over the 5-year period.

aging in general dentistry [3]. This is probably due to the fact that UNDH is largely, a teaching hospital for dental students who mostly utilize the radiographic services to diagnose general dental diseases such as caries, periapical pathology and periodontal conditions. The hospital has also well-established outpatient dental clinics which receive a high number of patients with dental diseases. With continued improvement, it has potential to teach not only under- and postgraduate students but also clinicians who may want to improve their intraoral imaging skills.

The extraoral techniques performed were about 1379 per year which was much lower compared to a study at Aarhaus University which involved 2374 digital extraoral images done within a year [6]. Panoramic imaging is one of the most commonly used extraoral radiographic technique in dentistry [3] which is also evident in 
the present findings. The volume of the panoramic examinations grew steadily from 2006 to 2008 . However, the services were temporarily interrupted in June 2009 due to equipment breakdown. This meant loss of some revenue which was already running at an average of 809 US\$ per month in 2009. Since the service was still required, outsourcing at a more expensive rate was resorted to. However, the services were restored with the purchase of new digital panoramic equipment.

The other extraoral radiographic techniques were minimally done at the UNDH. The low volume could be as a result of the number of patients seeking this service which is low or the shift by the clinicians to using more advanced forms of imaging such as CT and CBCT which are not available at UNDH.

Nonetheless, the conventional plain film imaging has been the examination of choice over the last century in the initial evaluation of maxillofacial pathological lesions as well as in determining the need for other projections [7]. However, the intrinsic limitations of conventional radiography include anatomic superimposition of structures, geometric distortion and lack of soft tissue imaging in addition to the examinations being technique sensitive [3]. Therefore, the need for other advanced imaging modalities such as conventional CT which is the technique of choice in the evaluation of most maxillofacial pathology since it gives excellent bone and soft tissue details [8]. Over the past decade CBCT has also increasingly replaced conventional dental radiological procedures [6]. It has been clinically applied in implantology, orthodontics, maxillofacial surgery and the assessment of dentoalveolar pathology $[9,10]$.

The volume of radiographs was found to have been low in November and December which corresponds to the examination and holiday season at UNDH. This could be an appropriate time for performing certain radiographic audits and equipment maintenance. More studies need to be carried out to determine the clinicians' attitude towards any existing imaging facility at teaching hospitals, factors that influence the range and volume of radiographs taken as well as identifying the investigation gaps.

This study emphasizes the importance of keeping good radiographic records without which such audits cannot be performed. It is paramount for dental institutions to keep up with the rapidly changing field of diagnostic imaging as well as offering optimal and prompt imaging services. Having an optimally equipped imaging center will enable prompt diagnosis and treatment, better patient satisfaction, monitoring of the diagnostic quality of the images, increased revenue generation and more importantly creation of a database of radiographic images which are necessary for cutting edge research and pro- fessional training. Notably, in Africa few dental schools offer postgraduate studies in radiology.

In conclusion, intraoral radiography was the commonest examination with bitewings having been the majority while panoramic imaging was the commonest extraoral technique performed. Results from this study provide baseline information that is beneficial to UNDH and other teaching dental institutions that plan to set up an oral and maxillofacial imaging department.

\section{ACKNOWLEDGEMENTS}

We appreciate the entire School of Dental Sciences administration at the University of Nairobi for granting the execution of this audit. We are greatly indebted to Mr. John Gacau and Mr. Patrick Chege for their meticulous register records and the excellent management of the radiography unit at the School.

\section{REFERENCES}

[1] Whaites, E. (1996) Essentials of dental radiography and radiology. Churchill Livingstone, London.

[2] Umarji, H.R. (2008) Concise oral radiology. Satish kumar Jain, CBS Publishers, New Delhi.

[3] White, S.C. and Pharoah, M.J. (2004) Imaging principles and techniques. In: Oral Radiology: Principles and Interpretation, 5th Edition. Mosby Company, St. Louis, 69264.

[4] Sikri, V.K. (2006) Fundamentals of dental radiology. 3rd Edition, Satish kumar Jain, CBS Publishers, New Delhi.

[5] Pendlebury, M.E., Horner, K. and Eaton, K.A. (2004) Selection criteria for dental radiography. 2nd Edition, Faculty of General Dental Practitioners (UK) Royal College of Surgeons of England, London.

[6] Wenzel, A. and Gotfredsen, E. (2005) Audit for extraoral radiographic examination in digital department. Dentomaxillofacial Radiology, 34, 228-230. doi:10.1259/dmfr/63732554

[7] Scarfe, W.C. (2005) Imaging of maxillofacial trauma: Evolutions and emerging revolutions. Oral Surgery, Oral Medicine, Oral Pathology, Oral Radiology, and Endodontics, 100, S75-S96.

[8] Boeddinghaus, R. and Whyte, A. (2008) Current concepts in maxillofacial imaging. European Journal of Radiology, 66, 396-418. doi:10.1016/j.ejrad.2007.11.019

[9] Kaeppler, G. (2010) Applications of cone beam computed tomography in dental and oral medicine. International Journal of Computerized Dentistry, 13, 203-219.

[10] De Vos, W., Casselman, J. and Swennen, G.R.J. (2009) Cone-beam computerized tomography (CBCT) imaging of the oral and maxillofacial region: A systemic review of the literature. International Journal of Oral \& Maxillofacial Surgery, 38, 609-625. doi:10.1016/j.ijom.2009.02.028 